\title{
PRIMEIRAS LINHAS SOBRE O CONTROLE DA VALIDADE DOS CONTRATOS COM FUNDAMENTO NA FUNCIONALIZAÇÃO DA LIBERDADE CONTRATUAL
}

\author{
GERSON LUIZ CARLOS BRANCO ${ }^{1}$
}

\begin{abstract}
RESUMO: O artigo apresenta ideias iniciais para contribuir sobre um debate em curso no Direito brasileiro, que é o da utilização da função social dos contratos como fundamento autônomo para invalidação de contratos ou cláusulas contratuais. O texto parte da perspectiva da liberdade contratual como direito fundamental e apresenta as hipóteses em que o ordenamento considera legítima a intervenção judicial para sua limitação, tratada a liberdade contratual não mais sob a ótica do dogma da vontade, mas como expressão da autodeterminação e da autonomia privada.

PALAVRAS-CHAVE: Liberdade Contratual; Autonomia Privada; Invalidade; Função Social dos Contratos; Direitos Fundamentais.
\end{abstract}

\begin{abstract}
This article show the initial ideas to give elements a present debate in the Brazilian law, which is the utilization of social function of contracts as a autonomous fundament to invalidation of contracts or his clauses. The text part of perspective of contractual freedom as a fundamental right and present the hypotheses in which the law consider legitimate the judicial intervention to his limitation, treating the contractual freedom not more under the optics of the will theory, but like the expression of auto determination and the private autonomy. KEYWORDS: Freedom Contract; Private Autonomy; Invalidity; Social Function of Contracts; Fundamental Rights.

SUMÁRIO: Introdução; I. Do Controle do Escopo pelo Legislador como Causa de Invalidade; II. Da Tipicidade Social e do Desvio Social Típico como Fundamento da Invalidade Contratual; Conclusão; Referências Bibliográficas.

SUMMARY: Introduction; I. Control of the ends by the Estatute law as a cause of Invalitidy; II. Social Tipification and Typical Deviation of Conduct as a Fundament of Contractual Invalidity; Conclusion; Bibliographical References.
\end{abstract}

Artigo recebido em 11.03.2011. Pareceres emitidos em 05.04.2011 e 23.05.2011.

Artigo aceito para publicação em 31.05.2011.

${ }^{1}$ Doutor em Direito Civil pela UFRGS. Professor de Direito Civil na PUC-RS, em Porto Alegre, RS e UNOESC, em Chapecó, SC. Advogado em Porto Alegre. gerson@gersonbranco.com.br 


\section{INTRODUÇÃo}

As tradicionais formas de invalidação dos contratos no Direito Civil do século $X X$ partiam da análise estrutural da relação contratual, evidenciando crédito e débito, com caráter neutro em relação aos sujeitos, cuja liberdade do ato de "declaração de vontade" era o elemento central.

Porém, os novos paradigmas do Direito Privado contemporâneo, em especial a partir do estudo sistemático da matéria e de sua compreensão histórica, cultural e inserida no quadro constitucional, afastaram a liberdade como uma expressão absoluta do 'dogma da vontade', para situá-la no contexto dos Direitos Fundamentais, em especial, do direito a autodeterminação.

Por isso, a liberdade contratual passou a ser compreendida não mais como um axioma, mas como uma das manifestações da personalidade, em um ordenamento no qual a pessoa é valor fonte de todo o Direito Privado, o que atribui um caráter funcional aos instrumentos necessários para a realização de tais valores, inclusive e principalmente ao contrato. ${ }^{2}$

O controle da validade dos contratos a partir de uma perspectiva funcional estabelece uma vinculação entre a relação de crédito e débito e sua origem, que não é mais uma "declaração de vontade", mas sua causa e, por isso, a partir da função prático-social à qual corresponde e que expressa sua disciplina, há a definição dos direitos, obrigações e poderes do credor. $^{3}$

Para tentar esclarecer como se insere a funcionalização do contrato no âmbito da teoria das invalidades, apresentamos dois caminhos que se pode visualizar como formas de construção de uma nova dogmática das invalidades em que a funcionalização da liberdade contratual passa a ser se não o principal, um dos principais fatores de invalidação.

\footnotetext{
${ }^{2}$ A respeito do processo de abertura do sistema, bem como a crise do modelo exegético, ver, entre outros ENGISCH, Karl. Introdução ao pensamento jurídico. 6. ed. Lisboa: Fundação Calouste Gulbenkian, 1988., assim como MARTINS-COSTA, Judith. As cláusulas gerais como fatores de mobilidade do sistema jurídico. Revista de Informação Legislativa, nº 112, p. 13-32. As cláusulas gerais descrevem fatos de maneira genérica que não permitem a construção de um silogismo perfeito com subsunção automática dos fatos do mundo com os fatos descritos em abstrato na norma. Para sua aplicação, é preciso que o juiz construa a regra do caso concreto levando em consideração as peculiaridades do caso e o princípio que se quer realizar através da cláusula geral, dentro dos limites ditados pelo legislador.

Sobre o tema da linguagem do Código Civil: a técnica das cláusulas gerais como instrumento de funcionalização e realização da socialidade e eticidade, ver BRANCO, Gerson Luiz Carlos. Função Social dos Contratos. São Paulo: Saraiva, 2009.

3 A busca da função está relacionada ao "aspecto causativo": "Ela assume uma disciplina segundo a sua causa, a qual é expressão da sua disciplina: o aspecto funcional e aquele causativo exprimem a mesma exigência, isto é, individuar e completar uma relação entre situações subjetivas. O credor, segundo seja a causa uma ou outra, tem, ou não, determinados poderes, obrigações...". PERLINGIERI, Pietro, tradução de Maria Cristina de Cicco. Perfis do Direito Civil. Introdução ao Direito Civil Constitucional. 2. ed. Rio de Janeiro: Renovar, 2002, p. 117.
} 


\section{DO CONTROLE DO ESCOPO PELO LEGISLADOR COMO CAUSA}

\section{DE INVALIDADE}

Evidentemente que o controle da funcionalização até recentemente era feito diretamente pelo legislador, que tutelava a função de maneira direta, estabelecendo o "escopo", como no caso das regras sobre locação e sobre o contrato de mútuo para financiamento habitacional, criando casos de invalidade no caso de não atendimento das regras expressas inseridas na lei. ${ }^{4}$

Exemplo disso é a seção IX da lei brasileira do inquilinato (Lei $n^{\circ}$ 8.245/91), destinada a regular as "nulidades", ao dizer em um único artigo que "São nulas de pleno direito as cláusulas do contrato de locação que visem a elidir os objetivos da presente lei, notadamente as que proíbam a prorrogação prevista no art. 47, ou que afastem o direito à renovação, na hipótese do art. 51, ou que imponham obrigações pecuniárias para tanto".

Ou seja, o interesse econômico socialmente típico foi identificado e tutelado de maneira direta pelo legislador, numa cláusula geral de proteção do escopo contratual, atribuindo como consequência do descumprimento do fim a ser atingido ou da burla a esse fim a invalidade do contrato ou da cláusula contratual.

Trata-se de um caso clássico em que se está dando vazão a uma exigência social de retirar da "álea do jogo e da procura e da oferta daqueles bens e serviços que, em número sempre crescente, são destinados a satisfazer exigências essenciais dos indivíduos", ou naqueles casos em que "a recusa se demonstre, nas circunstâncias de cada caso, lesiva à dignidade humana e à efetiva igualdade e liberdade" ${ }^{5}$

O legislador também define o escopo de maneira indireta por meio de expressões que não são explícitas, unívocas e taxativas, como são os casos da "natureza do bem, a peculiaridade dos sujeitos, etc".

Essas formas indiretas de funcionalização estão vinculadas em grande medida com causas de invalidade, como é o caso da regra do art. 473 do Código Civil brasileiro que toma em consideração a "natureza e o vulto dos investimentos" como determinante para a validade de cláusula contratual que fixa prazo para a denúncia unilateral do contrato em determinado prazo.

\footnotetext{
${ }^{4}$ No mesmo sentido de associar a concepção de "função" enquanto "finalidade" é o entendimento de Luis Renato Ferreira da Silva: "A ideia de função está presente no direito, no plano da compreensão global, quando se pensa em que o conjunto de regras positivas deve ter um tipo de finalidade e buscar alcançar certos objetivos. (...). Ao supor-se que um determinado instituto jurídico esteja funcionalizado, atribui-se a ele uma determinada finalidade a ser cumprida, restando estabelecido pela ordem jurídica que há uma relação de dependência entre o reconhecimento jurídico do instituto e o cumprimento da função". FERREIRA DA SILVA, Luis Renato. A função social do contrato no novo Código Civil e sua conexão com a solidariedade social. In: SARLET, Ingo Wolfgang (Org.). O novo Código Civil e a Constituição. Porto Alegre: Livraria do Advogado, 2003, p. 134.

${ }^{5}$ PERLINGIERI, Pietro, tradução de Maria Cristina de Cicco. Perfis do Direito Civil. Introdução ao Direito Civil Constitucional. 2. ed. Rio de Janeiro: Renovar, 2002, p. 289.

${ }^{6}$ PERLINGIERI, Pietro, Op. Cit., p. 292.
} 
Ou seja, o Código Civil brasileiro criou um mecanismo para negar a validade de disposição contratual, que for contrária à natureza da operação econômica subjacente, devendo o juiz moldar os efeitos do contrato tendo em vista o aspecto causativo da obrigação.

Apesar da reclamação já apresentada por Galgano e Irti a respeito da utilização do contrato como elemento de transição, não se pode negar que é o próprio legislador que manda considerar elementos fáticos na qualificação jurídica, acolhendo essa natureza dúplice do contrato através de expressões como o já mencionado art. 473 do Código Civil brasileiro em que a "natureza e o vulto dos investimentos" são elementos para invalidar cláusula contratual que permite denúncia do contrato em determinado tempo. ${ }^{7}$

A esse propósito são relevantes as ideias de Enzo Roppo, pela sua compreensão de que a função relevante do contrato não é propriamente jurídica, mas sua instrumentalidade exterior, vinculada à realidade econômica.

O contrato é compreendido como fenômeno econômico responsável pelas relações de troca e também como conceito jurídico. Este é a veste jurídico-formal daquele.

Isso significa que o contrato tem dupla dimensão, sendo a dimensão jurídica dependente da econômica, não obstante tenha certa autonomia que pode ser expressa de diversos modos e que está vinculada ao sistema jurídico de Direito Privado: o contrato é o instrumento para a circulação econômica.

Todavia, ao fato corresponde a norma segundo a qual o contrato deve corresponder à operação econômica, o que é evidenciado pela impossibilidade de dar-se contrato sem operação econômica, embora possa existir operação econômica sem contrato ${ }^{8}$.

Além disso, a funcionalidade contratual não é caracterizada pela simples necessidade de correspondência da veste jurídica à operação econômica, como é pela atuação estatal que por meio da tipificação legal dos contratos interfere nas relações econômicas para alcançar determinados fins, orientados por razões de política jurídica ${ }^{9}$.

\footnotetext{
7 A origem de tal disposição decorre da experiência jurisprudencial em torno do contrato de Distribuição Mercantil, quando investimentos substanciais eram realizados, e os prazos contratuais eram exíguos. A jurisprudência brasileira desde meados da década de 1970 passou a considerar tais prazos abusivos pela inconformidade com a natureza da operação econômica, em especial nos casos de distribuição de bebidas, combustível, etc. Sobre a matéria ver REALE, Miguel. Código Civil. Anteprojetos com Minhas Revisões, Correções, Substitutivos e Acréscimos. Texto inédito, não publicado, parcialmente manuscrito, s. d. REALE, Miguel. Questões de Direito Privado. São Paulo: Saraiva, 1997. REALE, Miguel e outros. Anteprojeto de Código Civil. Rio de Janeiro: Ministério da Justiça. Comissão de Estudos Legislativos, 1972.

${ }^{8}$ ROPPO, Enzo. O Contrato. Coimbra: Livraria Almedina, 1988, p. 19.

${ }^{9}$ Roppo cita como exemplo a intervenção no âmbito dos contratos agrários, lei do inquilinato e leis de proteção do consumidor, concluindo que "o direito dos contratos não se limita a revestir passivamente a operação econômica de um véu legal de per si não significativo, a representar a sua mera tradução jurídico-formal, mas, amiúde, tende a incidir sobre as operações econômicas
} 
A característica instrumental do contrato como mecanismo para realização de fins políticos exteriores à operação econômica, e também conformador das relações econômicas sob o ponto de vista macroscópico, caracteriza sua autonomia como conceito jurídico e também confere autonomia ao direito dos contratos.

$E$, nesse sentido, a ideia de funcionalização e uma cláusula geral da função social dos contratos como é a do art. 421 do Código Civil brasileiro também serve como um instrumento de invalidação das disposições contratuais quando o instrumento contratual não tem correspondência com a operação econômica subjacente.

O art. 421 do Código Civil brasileiro contém definição geral de escopo ao determinar que "a liberdade de contratar será exercida em razão e nos limites da função social dos contratos".

As três hipóteses acima passam pela análise da correspondência entre o contrato e a operação econômica subjacente, o que gera uma nova pergunta: quando o juiz pode identificar a correspondência ou falta de correspondência?

A resposta não é fácil e consiste numa das questões centrais do problema da invalidação com fundamento na funcionalidade do contrato, o que nos remete à noção de função social típica.

\section{DA TIPICIDADE SOCIAL E DO DESVIO SOCIAL TÍPICO COMO FUNDAMENTO DA INVALIDADE CONTRATUAL}

A proposição deste trabalho é de que além da fixação direta (lei do inquilinato), indireta (natureza ou vulto dos investimentos) ou geral (cláusula geral do art. 421 do $\mathrm{CCB}$ ) da funcionalização do contrato, as hipóteses gerais de invalidação dependem dos conceitos de função social típica e desvio social típico, fornecidos em especial e respectivamente por Emílio Betti e Joaquim de Souza Ribeiro.

A invalidação dos contratos ou de cláusulas contratuais a partir da compreensão funcional do contrato se dá pela compatibilidade entre os fins que se pretendem alcançar por meio da declaração negocial, e os fins que tipicamente são reconhecidos como socialmente úteis e relevantes.

Ou seja, o Direito Contratual contemporâneo apresenta uma espécie de "dualidade de espaços normativos" em que a liberdade contratual é acolhida em graus diferenciados, pois, ao mesmo tempo que é reconhecida de maneira extremamente ampla em face de ser uma eficácia dos direitos fundamentais, sofre limitações de conteúdo, "de tal modo que estipulações perfeitamente válidas em face da disciplina comum são feridas de nulidade quando caem dentro do âmbito de aplicação da disciplina de tutela". ${ }^{10}$

(ou até sobre a sua dinâmica complexiva), de modo a determiná-las e orientá-las segundo objetivos que bem se podem apelidar de políticos lato sensu". ROPPO, E. Op. Cit., p. 23.

${ }^{10}$ RIBEIRO. Joaquim de Souza. A Boa Fé como Norma de Validade. In: Direito dos Contratos, Coimbra: Coimbra Editora, 2007, p. 225. 
Esse é o aspecto mais relevante da compreensão de que a liberdade contratual tem status constitucional, é decorrência direta dos direitos gerais de liberdade, previstos no art. $5^{\circ}$ da Constituição Federal, cuja natureza de Direito Fundamental permite uma interpretação integrada e sistemática do princípio que lhe é inerente e também dos valores que o contrato é chamado a realizar.

Assim como serve a liberdade de iniciativa, também serve a função social previstas no art. 171 da Constituição Federal e a falta de correspondência do contrato com a principiologia constitucional tem por consequência a invalidade da disposição contratual, por força de disposição expressa do Código Civil vigente, que rejeitou a máxima francesa pas de nulite sans texte para adotar a regra do art. 166, VII, segundo o qual é nulo o negócio jurídico quando a lei "proibir-Ihe a prática, sem cominar sanção".

Ou seja, trata-se de verdadeira cláusula geral das invalidades que passou a permitir que a primeira consequência para a falta de correspondência entre o contrato e as normas jurídicas que disciplinam a matéria é a invalidade da disposição contratual.

A cláusula geral da função social dos contratos outorgou ao juiz a legitimidade para perquirir a "razão" da celebração do contrato. Essa razão sob o ponto de vista jurídico não pode ser a razão individual, particular e subjetiva, que são os motivos do contrato: são as razões que comumente acompanham os contratos, a razão objetiva, que é identificada em nosso ordenamento como a causa do contrato ${ }^{11}$.

A crítica tradicional a tal concepção está no fato de que Betti ao propô-la pressupõe uma tipicidade social em todos os contratos. Isso tem como óbice prático a circunstância de que todos os novos contratos conhecidos como socialmente típicos somente adquiriram tal característica após sua incorporação ao modus vivendi de dada coletividade. Porém, antes disso, em algum momento, foram estrita novidade, fruto da criatividade e do empreendedorismo privado.

Essa crítica é inafastável.

Ou seja, os contratos têm por característica a atipicidade e isso lhes dá flexibilidade para que a livre iniciativa e a criatividade empresarial enriqueça a cada dia nossa vida econômica e jurídica com novos modelos e operações econômicas, cujo reflexo são novos contratos e novos modos de contatar. ${ }^{12}$

\footnotetext{
${ }^{11}$ Fica superada a concepção segundo a qual o "elemento categorial inderrogável" é a estrutura jurídica e não a função, que não poderia influenciar na produção dos efeitos, mas somente sobre a atuação do legislador, tal como sustentando por AZEVEDO, Antonio Junqueira de. Negócio jurídico - existência, validade e eficácia. 3. ed. São Paulo: Saraiva, 2000, p. 148 e 149: "A função, portanto, influi enormemente como ratio juris da norma, mas não diretamente sobre o negócio".

${ }_{12} \mathrm{O}$ Direito brasileiro reconheceu expressamente a possibilidade de criação de contratos atípicos em seu art. 425 tal como o Código Civil italiano.
} 
A atipicidade legal é a regra. Isso é indiscutível. Contudo, o sistema de controle implantado com a cláusula geral da função social dos contratos passou a exigir a adequação funcional destes, que impõe o controle da tipicidade como mecanismo de validação do conteúdo socialmente útil, justo e livre. A liberdade de contratar foi condicionada pela necessidade do cumprimento de sua função social, por isso os contratos precisam ter um conteúdo reconhecível como socialmente relevante e útil, sendo também indispensável que também realizem um ato de autodeterminação, já que permanecem plenamente em vigor as regras que protegem a liberdade da declaração de vontade.

A diferença entre ter como princípio a funcionalização ou uma cláusula geral da função social dos contratos e um sistema com forte caráter individualista não é a ausência de controle dos fins, pois já se sustentava que "o escopo atípico se há de justificar como digno da tutela do direito, reflectido certa utilidade tanto particular como colectiva". Em sistemas com caráter social mais marcante como são os Códigos brasileiro, italiano e português o controle é "mais apertado e eficaz"13.

Uma disposição como a do Art. 425 do Código Civil brasileiro ${ }^{14}$ e a lembrança de que a liberdade de contratar não perde sua natureza ao ser funcionalizada são mecanismos para que o caráter conservador do Direito não emperre o desenvolvimento social e, consequentemente, jurídico. ${ }^{15}$

A liberdade contratual não é liberdade para fazer o que se quer, mas o poder de ordenar os próprios interesses em uma dimensão social, na qual não se pode deixar de compreender a essencial relatividade histórica do que se qualifica como "típico" segundo o ordenamento vigente ${ }^{16}$.

A natureza social do ato de contratar (vincular-se) se dá pela interpenetração de duas esferas de liberdade. A partir do momento em que ocorre a declaração negocial, ou até mesmo antes, no processo de aproximação para celebração do contrato, a liberdade individual cede lugar a um regulamento que sai da disponibilidade de qualquer das partes e assume uma conotação social, com uma função a cumprir.

A esse respeito a concepção de Betti contextualiza que a função social típica não obedece mais a esquemas rígidos como os romanos, em que o tipo do negócio era determinante para que se pudesse ter uma actio,

${ }^{13}$ CARVALHO, Orlando de. Negócio Jurídico Indirecto. Boletim da Faculdade de Direito de Coimbra, Coimbra, 1951, suplemento X, p. 16

14 "Art. 425. É lícito às partes estipular contratos atípicos, observadas as normas gerais fixadas neste Código".

${ }^{15}$ Também se deve considerar que a disposição do artigo 425 contrasta com a regra da tipicidade estrita dos negócios jurídicos unilaterais, o que revela outra dimensão da liberdade contratual, que é seu caráter social e cooperativo. Não basta a declaração autovinculativa do sujeito para o nascimento de uma obrigação válida, ainda que haja plena liberdade no ato de vontade, pois a tipicidade estrita dos negócios jurídicos unilaterais impede tal eficácia.

${ }^{16}$ BETTI, Emilio. Negozio Giuridico. In: Novissimo Digesto Italiano, p. 216. 
não havendo qualquer esquematismo em relação à tipicidade. Atualmente, as causas são típicas sem ser taxativamente indicadas pela lei, mas por serem "admitidas pela consciência social, como correspondendo a uma necessidade prática legítima, a um interesse social duradouro, e, como tais, são dignas de tutela jurídica". Podem ser determinadas por concepções dominantes na "consciência social da época, nos vários campos da economia, da técnica e da moral"17.

Essa tipicidade social tem a função de orientar e limitar a autonomia privada, sendo mais elástica na conformação dos tipos. Remetem "para as valorações econômicas ou éticas da consciência social", havendo menção expressa do autor italiano ao fato de tal concepção haver sido adotada no artigo 1.322 do Código Civil italiano, bem como nos artigos $1.174^{18}$ e 1.325, $2^{0^{19}}$, do mesmo diploma legal ${ }^{20}$. A análise feita diz respeito ao condicionamento da possibilidade de escolha dos tipos, os interesses dignos de tutela, e não a possibilidade em si, a liberdade de celebração de negócios atípicos.

Sobre o tema da invalidação de contratos ou de cláusulas contratuais é de extrema importância a concepção de Joaquim de Sousa Ribeiro, ao afirmar que todo e qualquer critério meramente sistemático, partindo de uma compreensão funcional dos contratos, para delimitar o alcance da "liberdade contratual" como instrumento de realização da autodeterminação, que não caracterize imposição ditada por condições exógenas ao contrato, está fadado ao fracasso.

O autor português, tratando sobre a invalidação das cláusulas abusivas por razões funcionais, após extensa análise de várias concepções e proposições para definição dos critérios para intervenção judicial visando alcançar uma "justiça contratual" em razão das insuficiências do "mecanismo contratual", chega à conclusão de que o único ponto de apoio seguro para a intervenção judicial está na análise da tipicidade de determinados desvios, que provocam uma conformação desequilibrada de interesses, em prejuízo de uma categoria de contraentes ${ }^{21}$.

${ }^{17}$ BETTI, E. Teoria Geral do Negócio Jurídico, v. I, Coimbra: Editora Coimbra, 1969, p. 373

18 "Artigo 1174 Carattere patrimoniale della prestazione. La prestazione che forma oggetto dell'obbligazione deve essere suscettibile di valutazione economica e deve corrispondere a un interesse, anche non patrimoniale, del creditore (Cod. Civ. 1.256 e seguente, 1.411 e seguenti." 19 "Artigo 1.325 Indicazione dei requisiti.vl requisiti del contratto sono: 1) l'accordo delle parti (1.326 e seguenti, 1.427); v2) la causa (1.343 e seguenti); v3) l'oggetto (1.346 e seguenti); 4) la forma, quando risulta che è prescritta dalla legge sotto pena di nullità (1.350 e seguenti)." ${ }^{20}$ BETTI, E. Teoria Geral do Negócio Jurídico, v. I, p. 374.

${ }^{21}$ Obra que faz análise da funcionalidade e seu vínculo com as condições gerais dos negócios é a de RIBEIRO, Joaquim de Sousa. RIBEIRO, Joaquim de Sousa. O Problema do Contrato as Cláusulas Contratuais Gerais e o Princípio da Liberdade Contratual. Coimbra: Almedina, 2003. A questão da tipicidade não diz diretamente com a limitação da eficácia de cláusulas inseridas em "contratos de adesão" ou "contratos submetidos às condições gerais dos negócios", regulamentados nos artigos 423 e 424 do Código Civil, tampouco com os limites decorrentes da tipicidade legal, como são as disposições relativas ao preço da compra e venda etc. Embora o debate jurídico a respeito da funcionalidade do contrato tenha nexo direto com as condições 
A tipicidade de que trata Joaquim de Sousa Ribeiro é o desvio social típico, que caracteriza formas reconhecidas empiricamente, com atributos sociais típicos e desvios com resultados gravosos e não equitativos.

Esse desvio típico também é acompanhado por um prejuízo típico, "observável na prática negocial", que demonstra o desvirtuamento da função de ordenação da autonomia privada.

Sob esse aspecto há um severo limitador da atividade judicial de intervenção nos contratos, pois nessa concepção a necessidade de preservar o contrato como instrumento de regulação exige que não haja intervenção judicial, salvo naqueles casos em que tipicamente fica caracterizado o desvio funcional, o que tem razão de ser na necessidade de segurança jurídica inerente ao contrato:

É também por razões de certeza e segurança que se prendem, não apenas com a tutela da confiança individual na eficácia do acordo, mas também com o papel do contrato como instrumento de ordenação: esta seria irremediavelmente prejudicada se os seus efeitos vinculativos pudessem ser permanentemente postos em causa, com a alegação de factores atípicos de desresponsabilização ${ }^{22}$.

O método de verificação, portanto, das condições de intervenção judicial para decretação da invalidade é baseado na verificação empírica de adequação de uma generalidade de situações negociais típicas em que ocorre a distorção funcional da liberdade contratual.

Para isso, é necessário "integrar-se o contrato concreto numa categoria de contratos" em que as condições negociais são similares para aplicação de determinada disciplina jurídica, e, assim fazer o controle do conteúdo do contrato a partir dos parâmetros valorativos respectivos ${ }^{23}$.

\section{CONCLUSÃo}

Essas primeiras observações sobre a funcionalidade como causa autônoma de invalidação dos contratos situa a autodeterminação como elemento essencial ao processo de intervenção judicial.

Somente será caso de intervenção para adequação funcional do contrato, aquele em que uma das partes indique "uma típica incapacidade de autotutela" ou quando não se possa realizar os valores que dão sentido à autonomia privada em razão da inexistência das "condições de regulação de interesses privados em autodeterminação" ${ }^{24}$.

gerais dos negócios, pois é nesse âmbito que têm sido problematizados os limites para intervenção e controle judicial do conteúdo do contrato, essa é apenas uma perspectiva, que não está no centro da tese.

${ }^{22}$ RIBEIRO, Joaquim de Sousa. Op. cit. p. 172.

${ }^{23}$ RIBEIRO, Joaquim de Sousa. Op. cit. p. 175.

${ }^{24}$ RIBEIRO, Joaquim de Sousa. Op. cit. p. 174-176. 
Fora dessa hipótese não há como realizar a intervenção judicial para decretação da invalidade de cláusula contratual com fundamento único na cláusula geral do art. 421 do Código Civil.

Há casos em que a falta de autodeterminação é evidente, como nas relações massificadas, nas quais não há qualquer espaço para que os agentes possam exercitar com mínima liberdade a autorregulação, como nos contratos de crédito ao consumo, matéria que está regulada de maneira substancialmente clara no art. 51 do Código de Defesa do Consumidor, que se pode dizer é uma das hipóteses claras de definição do escopo pelo próprio legislador.

Ou seja, nas hipóteses de que trata o art. 51 do Código de Defesa do Consumidor, a invalidade da cláusula contratual é encontrada porque o legislador de forma expressa definiu fins e funções que precisam ser alcançadas ou que são vedadas, outorgando a juiz o papel de aplicar as diretrizes funcionais expressas na lei.

Porém, fora do Direito do Consumidor, em especial nas relações civis e no âmbito do Direito Empresarial, há situações em que o juiz precisará analisar o caso concreto para identificar se uma das partes teve ou não condições de contribuir para a formação do regulamento, caso dos contratos de distribuição, nos quais a parte teoricamente mais fraca pode possuir uma posição estratégica na relação, que lhe permite opinar e definir o conteúdo do regulamento contratual.

Nesses casos não há um escopo definido pelo legislador e será necessário que a técnica de aplicação da cláusula geral seja utilizada, mediante a reconstrução da norma para aplicá-la no caso concreto.

Para tanto são de grande valia os recursos à "tipicidade social" de Betti e a tipicidade decorrente dos "dados empíricos fornecidos pela mutável prática negocial" de Joaquim de Sousa Ribeiro. Embora tenham matrizes completamente distintas, o instrumento de controle do conteúdo do contrato que é apresentado por ambos é muito similar, pois, enquanto um trata da tipicidade dos desvios, o outro trata da tipicidade do contrato, tal qual um espelho côncavo, que na distância focal correta gera imagens reais, porém invertidas.

A similitude deriva do fornecimento de um critério concreto para a construção da decisão judicial, independentemente da existência de regras gerais e abstratas ou de princípios cuja generalidade dão margem à arbitrariedade, já que a decretação da invalidade de cláusulas contratuais atinge diretamente $\mathrm{o}$ direito fundamental a autodeterminação na sua expressão mais importante que é a autonomia privada, compreendida como competência para a nomogênese.

Ao manusear com a limitação de direitos fundamentais em razão de sua funcionalidade não poderá o juiz buscar a solução do caso concreto em parâmetros subjetivos ou em fundamentos metafísicos. É preciso analisar 
aquilo que tipicamente ocorre na realidade econômica e social, a quem o direito serve: a regulação das relações intersubjetivas, para o autor italiano; a ordenação dos interesses privados, para o autor português.

De qualquer maneira permanece certa "fluidez" na ideia de "interesses dignos de tutela", o que somente pode ser desvendado com a utilização de recursos como os da ética da situação desenvolvida por Miguel Reale, para quem o Juiz ao examinar uma cláusula geral do gênero será obrigado a definir o que é "interesse digno de tutela" ou mesmo a identificação de uma "prática legítima" a partir dos padrões éticos do homem situado tanto sob o ponto de vista histórico como geográfico, submerso na carga cultural que the é inafastável ${ }^{25}$.

Por essa razão, a perspectiva de construção de elementos que deixem mais claro o propósito deste texto passa pela análise de casos para aproximar os problemas teóricos com as possibilidades concretas das decisões judiciais da maneira e nos limites do que se pode fazer, o que já é tema para outras linhas.

\section{REFERÊNCIAS BIBLIOGRÁFICAS}

AZEVEDO, Antonio Junqueira de. Negócio Jurídico - existência, validade e eficácia. 3. ed., São Paulo: Saraiva, 2000.

BETTI, Emilio. Teoria Geral do Negócio Jurídico. v. I, Coimbra: Editora Coimbra, 1969. BETTI, Emilio. Negozio Giuridico. In: Novissimo Digesto Italiano. Torino, 1957.

BRANCO, Gerson Luiz Carlos. Função Social dos Contratos. São Paulo: Saraiva, 2009. CARVALHO, Orlando de. Negócio Jurídico Indirecto. Boletim da Faculdade de Direito de Coimbra. Coimbra, 1951, Suplemento X.

ENGISCH, Karl. Introdução ao Pensamento Jurídico. 6. ed., Lisboa: Fundação Calouste Gulbenkian, 1988.

FERREIRA DA SILVA, Luis Renato. A Função Social do Contrato no Novo Código Civil e sua Conexão com a Solidariedade Social. In: SARLET, Ingo Wolfgang (Org.). O Novo Código Civil e a Constituição. Porto Alegre: Livraria do Advogado, 2003, p. 134.

MARTINS-COSTA, Judith; BRANCO, Gerson. Diretrizes Teóricas do Código Civil. São Paulo: Saraiva, 2002.

MARTINS-COSTA, Judith. As Cláusulas Gerais como Fatores de Mobilidade do Sistema Jurídico. Revista de Informação Legislativa, $\mathrm{n}^{\circ}$ 112, p. 13-32.

PERLINGIERI, Pietro. Tradução de Maria Cristina de Cicco. Perfis do Direito Civil. Introdução ao Direito Civil Constitucional. 2. ed., Rio de Janeiro: Renovar, 2002.

\footnotetext{
${ }^{25}$ MARTINS-COSTA, Judith, Diretrizes Teóricas, p. 131. "As regras jurídicas jamais são um 'dado', antes constituindo um 'construído' por realizarem-se sempre na história, consubstanciando, assim, uma das privilegiadas dimensões da cultura. Se esta afirmação é correta para o Direito em sua integralidade, sua adequação ressalta particularmente no Direito Civil, que é o direito das pessoas que vivem na cive, traçando as regras aplicáveis às pessoas enquanto pessoas, dos 'homens enquanto homens', os quais se relacionam, no entanto, em necessária comunidade".
} 
REALE, Miguel e outros. Anteprojeto de Código Civil. Rio de Janeiro: Ministério da Justiça. Comissão de Estudos Legislativos, 1972.

REALE, Miguel. Código Civil. Anteprojetos com Minhas Revisões, Correções, Substitutivos e Acréscimos. Texto inédito, não publicado, parcialmente manuscrito, s. d. REALE, Miguel. Questões de Direito Privado. São Paulo: Saraiva, 1997.

RIBEIRO, Joaquim de Sousa. O Problema do Contrato as Cláusulas Contratuais Gerais e o Princípio da Liberdade Contratual. Coimbra: Almedina, 2003.

RIBEIRO, Joaquim de Souza. A Boa Fé como Norma de Validade. In: Direito dos Contratos, Coimbra: Coimbra Editora, 2007.

ROPPO, Enzo. O Contrato. Coimbra: Livraria Almedina, 1988. 